\title{
CARDIOVASCULAR RISK ASSOCIATED WITH ANDROGEN DEPRIVATION THERAPY IN ADVANCED PROSTATE CANCER
}

\author{
DEEPTHI C DENNY*, YOGAVADULA SS, VIJAY R, MOHAMED FARDAN, DIVYA SARA IYPE, ABI MAHESHWARAN K
}

Department of Pharmacy Practice, PSG College of Pharmacy, Coimbatore, Tamil Nadu, India. Email: deepthycdenny@gmail.com

Received: 24 April 2021, Revised and Accepted: 07 June 2021

ABSTRACT

Cancer is a lethal disease that is the second leading cause of mortality in the world. According to statistics, prostate cancer is one of the most common types among men. Male hormone androgens, particularly testosterone, are required for normal growth and functioning of the prostate. In prostate cancer, activation of the androgen receptor promotes the growth of cancer cells. The goal of hormonal therapy or androgen deprivation therapy (ADT) is to reduce levels of such male hormones in the body or prevent them from stimulating cancer cells. There are many issues that have to be considered before initiation of hormonal therapy which are necessary to be aware of for its prevention and the management in routine clinical practices. In this review article, we emphasis on cardiovascular complications following ADT and certain treatment measures.

Keywords: Prostate cancer, Androgen deprivation therapy, Testosterone, Cardiovascular complications, Gonadotropin-releasing hormone agonist.

(c) 2021 The Authors. Published by Innovare Academic Sciences Pvt Ltd. This is an open access article under the CC BY license (http://creativecommons.org/ licenses/by/4.0/) DOI: http://dx.doi.org/10.22159/ajpcr.2021v14i8.41946. Journal homepage: https://innovareacademics.in/journals/index.php/ajpcr

\section{INTRODUCTION}

Althogh prostate cancer is a global health problem, it is a common cancer in men and on the Asian continent it is only now found to be increasing rapidly [1-4]. Changing lifestyles may remain one responsible factor for this [5]. The global incidence is 1:52 in men aged 50-59 years, and nearly $60 \%$ in men aged 60 and up [6]. In India, there is a significant variation in incidence, disease characteristics and mortality rate, with the incidence being considerably higher in the urban population. Localized prostate cancer can be controlled by surgery or radiation therapy [7-9], but advanced prostate cancer was not curable. Treatment for advanced prostate cancer was mainly palliative care, which provides symptom relief and maintains the quality of life. However, now the advancement of androgen deprivation therapy (ADT) is a key therapeutic intervention in men with advanced prostate cancer [10]. Hormone therapy has been shown to enhance clinical and pathological characteristics in early prostate cancer patients [11]. The mainstay of treatment for metastatic prostate cancer is the administration of a gonadotropin-releasing hormone $(\mathrm{GnRH})$ agonist on a long-term basis [12]. ADT is the use of an orchiectomy or a luteinizing hormone releasing hormone (LHRH) agonist to manipulate the hypothalamicpituitary-gonadal axis to attain castrate levels of testosterone $[13,14]$. ADT causes adverse effects including bone loss, metabolic changes, gynecomastia, muscle loss, hot flash and cardiovascular (CV) complications [15]. We conducted a review that focuses predominantly on the CV complications of ADT. In 2006, awareness of the problem began with the publication of an observational surveillance, epidemiology and end results (SEER)-Medicare study by Keating et al. [16] The US Food and Drug Administration issued a drug safety communication in 2010 requiring manufacturers of GnRH agonists to change their labeling to include a warning about "increased risk of diabetes and certain CV diseases (CVDs) (heart attack, sudden cardiac death, and stroke)" [17]. Following that, various reviews on ADT and its negative effects were released. In this narrative review we aim to improve awareness of the relationship between long-term Androgen Deprivation associated with increased risk of $\mathrm{CV}$ complications along with the management measures for patients developing $\mathrm{CV}$ complications.

\section{PATHOGENESIS}

Testosterone is the major male hormone primarily produced by testes $[18,19]$. LHRH, also known as GnRH controls this process by regulating Luteinizing hormone production by the anterior pituitary gland. Only $90 \%$ of testosterone is produced by the testes, with the remaining $10 \%$ derived from adrenal steroid synthesis. The weak androgens dehydroepiandrosterone and androstenedione secreted by the adrenal glands are converted to testosterone in peripheral tissues and prostate gland [20]. Androgens are essential for the development, growth and functioning of the prostate. Testosterone diffuses along a concentration gradient into the prostate. Five- $\alpha$ reductase reduces Testosterone to dihydrotestosterone (DHT). DHT is the primary androgen that controls cell division in the prostate gland. DHT possesses higher affinity towards prostate tissues and is twice as potent as testosterone for prostate growth stimulation [21]. The beneficial clinical effects of suppressing serum testosterone levels in men with advanced prostate cancer was first found by Huggins and Hodges in the year 1941, for which they received the Nobel prize in the year 1966 [9]. In addition, ADT is universally accepted as a treatment for symptomatic metastatic prostate cancer. CV effects of androgens in normal/pathological conditions can lead to either positive or negative effects. Androgens play a role in the modulation of vascular endothelium tone, proliferation, motility, adhesion, and anti-thrombotic characteristics. These hormones equally participate in important pathogenic mechanisms such as vascular inflammation and these structural changes contribute to plaque and thrombus formation in the vessels $[22,23]$. Another study reveals that loss of androgens in men leads to an increase in aortic stiffness and serum insulin, which contributes to an increase in CV risk [24]. The alleged mechanism underlying the association of $\mathrm{ADT}$ with elevated risk of $\mathrm{CV}$ events in patients with prostate cancer is hypothetical. However, it's thought to be linked to ADT-induced metabolic and immunomodulatory alterations that destabilize pre-existing atherosclerotic plaque in people who have already had a heart attack or stroke, potentially accelerating the progression of atherosclerosis. One possibility is that potential cardioprotection provided by testosterone is disrupted by ADT. Another theory is that circulating $\mathrm{T}$ lymphocytes that can express the GnRH receptor become activated and penetrate atherosclerotic plaque, disrupting the fibrous cap and destabilizing the plaque [25]. The causes of the inequalities are unknown; however, they may be related to vascular endothelial heterogeneity and androgen-specific effects on men and women [22]. Reduction of androgen levels may contribute to risk factors for CVDs such as obesity, hyperlipoproteinemia, hypertension and diabetes mellitus. A randomized control trial by Smith et al. found 
that administration of $\mathrm{GnRH}$ agonists such as Leuprolide causes body composition changes associated with $\mathrm{CV}$ risk, including increased body fat (9.4-11.2\%), decreased lean muscle mass (2.7-3.6\%), hyperlipoproteinemia, especially increased levels of high-density lipoprotein (HDL) [26]. Hormonal agents used in prostate cancer are given in Table $1[27,28]$

\section{ADT ASSOCIATED CV RISK}

CVD remains the leading cause of death worldwide, with over 17 million deaths per year and a projected increase to over 23.5 million by 2030 is expected [29]. The majority of evidence establishing a link between ADT and CVD is observational in nature. Even short-term administration of ADT might cause osteoporosis, obesity, sarcopenia, lipid changes, insulin resistance, and an elevated risk of diabetes and CV morbidity, to name a few [30]. An Italian real-world analysis shows that the majority of patients received GnRH agonists rather than a GnRH antagonist [31]. SEER Medicare data for this analysis cohort included 73,196 men with locoregional prostate cancer. In men, GnRH agonists are linked to an increased risk of diabetes, coronary heart disease, myocardial infarction (MI), and sudden cardiac death, while orchiectomy was not linked to any of these events [16]. In a univariate analysis of a population-based study, the prevalence of two CVD risk factors, hypertension and diabetes, was found to be higher in the ADT group than in men not receiving ADT. Those who had ADT after being newly diagnosed with prostate cancer had a $20 \%$ higher risk of significant CVD morbidity than men who did not receive ADT. Given the contribution of CVD to mortality in men with low risk or intermediate risk disease, those patients who undergo adjuvant or neoadjuvant ADT for even a brief duration may actually experience decreased survival as a result of the intervention [21]. According to the Cancer of the Prostate Strategic Urologic Research Endeavor database, this study looked at data from 3262 individuals who had a radical prostatectomy and 1630 individuals who had localized prostate cancer and were treated with external beam radiation therapy, brachytherapy or cryotherapy. After correcting for age (a continuous variable) and the presence of baseline CVD risk factors, competing risk regression analyses were conducted to see if using ADT was related to a shorter time to death due to CV causes. According to the findings, ADT use was linked to a statistically significant increase in the risk of death from CVD-related causes in patients managed with radical prostatectomy. ADT use was coupled with a significant cumulative incidence of untimely onset of fatal MI and death due to CVD causes among patients aged 65 and older who underwent brachytherapy, external beam radiation treatment or cryotherapy, although the difference did not attain statistical significance [32,33]. Tsai et al. through his study demonstrated that after managing for age and CVD risk factors, ADT use was associated with shorter time to death from CV causes [32].

\section{SPECIFIC DRUG-BASED STUDIES}

A prospective study conducted by Smith et al. compared leuprolide monotherapy with bicalutamide monotherapy on metabolic changes. Evaluation of subjects was performed at baseline, 3 months, 6 months, 9 months, and 12 months and found that GnRH agonists preferentially increase subcutaneous fat, increase HDL cholesterol and adiponectin levels, and do not change the

Table 1: Hormonal agents used for androgen deprivation in prostate cancer

\begin{tabular}{|c|c|c|c|}
\hline LHRH agonist & $\begin{array}{l}\text { LHRH } \\
\text { antagonists }\end{array}$ & $\begin{array}{l}\text { Anti- } \\
\text { androgens }\end{array}$ & $\begin{array}{l}\text { Newer anti-androgens } \\
\text { (second generation } \\
\text { anti-androgens) }\end{array}$ \\
\hline Leuprolide & Degarelix & Flutamide & Enzalutamide \\
\hline Goserelin & Relugolix & Bicalutamide & Apalutamide \\
\hline Triptorelin & Abiraterone & Nilutamide & Darolutamide \\
\hline Histrelin & & & Abiraterone \\
\hline
\end{tabular}

LHRH: Luteinizing hormone releasing hormone waist-to-hip ratio, blood pressure, or C-reactive protein levels [34]. According to The Early Prostrate Cancer Trail, bicalutamide showed significant improvement in progression free survival irrespective of primary therapy [35]. Three randomized Phase III trials conducted by Garnick et al. compared GnRH antagonist Abarelix to either Goserelin plus Bicalutamide $(\mathrm{G}+\mathrm{B})$; Leuprolide (L) monotherapy; or Leuprolide plus Bicalutamide $(\mathrm{L}+\mathrm{B})$ in patients with prostate cancer undergoing initial hormonal therapy and included patients with Stage D1/D2 disease, rising prostate specific antigen, intermittent hormonal therapy or neoadjuvant hormonal therapy. It was discovered that hormonal therapy which induces androgen deprivation are all associated with QT interval prolongation [36]. A meta-analysis of an observational study conducted by Garnick et al. indicated a favorable link between ADT, notably GnRH agonist (Leuprolide, Goserelin), orchiectomy and the occurrence of CVD events. When compared to males with prostate cancer who were not treated with ADT, GnRH agonists were related to a $38 \%$ greater risk of any type of non-fatal CVD [37]. A study conducted by Dockery et al. included 43 men with prostate cancer randomly assigned to goserelin or bicalutamide. In a 6-month follow-up they detected an increase in N-terminal pro B-type Natriuretic Peptide which could imply on CV risk following hormonal manipulation [38]. According to a meta-analysis of randomized controlled trials using abiraterone and enzalutamide, abiraterone was linked to an increased risk of CVD, whereas enzalutamide was linked to an increased risk of fatigue [39].

\section{OTHER RISK EVENTS ASSOCIATED WITH ADT}

Men who take ADT for prostate cancer suffer from a variety of side effects [40]. Hypertension increases with age [41-44], where approximately $70 \%$ of individuals represent 65 years and older. Hypertension is a factor in one out of every seven deaths, and hypertension impacts $70 \%$ of people who suffer their first heart attack or stroke [45]. Treatment with new hormonal agents increased the risk of hypertension by $98 \%$. Abiraterone caused $26.2 \%$ and $6.9 \%$ of all-grade and high-grade hypertension, respectively. There was a significant heterogenicity in all grades hypertension [46]. In an observational study of patients with local or regional prostate cancer in the Veterans Healthcare Administration, it was identified that there exists an association of GnRH agonist and stroke but the mechanism of association was unknown. It was assumed to be the same physiological changes proposed to underlie the risk of CV disease [47]. Induction of hemodynamic and metabolic changes by AST may trigger MI in a predisposed man [48]. A nested case-control study adds to the evidence that ADT may increase the risk of stroke or transient ischemic attack [49]. A total of 239,099 patients from ten trials were included in the meta-analysis. Stroke risk was significantly raised in patients managed with GnRH agonists, orchiectomy, or oral anti-androgens [50]. Although many studies show evidence of CV and cerebrovascular complications following ADT for prostate cancer, few studies have disproved this claim. In a population based observational study consisting of 6,556 men who received GnRH agonist and 3,330 men who underwent orchiectomy as primary treatment, there was no risk of increased CVD among men on GnRH agonist compared to men who had undergone orchieoctomy [51]. Several studies have found that CV events occur more frequently within the first 12 months of starting ADT [52]. A meta-analysis of more than 4,000 patients could not gather any evidence that ADT increases CV death among men. On the contrary, they observed a relationship between ADT and enhanced prostate cancer specific survival [53]. Discrepant findings can be accounted for by methodological limitations of observational and randomized studies with respect to association with ADT and CVD [54].

\section{MANAGEMENT}

ADT has been shown to improve survival for men with intermediate and high-risk prostate cancer [55-57]. Chemo-hormonal therapies are being studied by many researchers [58-60]. Although certain studies suggest preventive treatments with lipid lowering agents, 
Table 2: ABCDE steps to reduce CVD in patients with prostate cancer

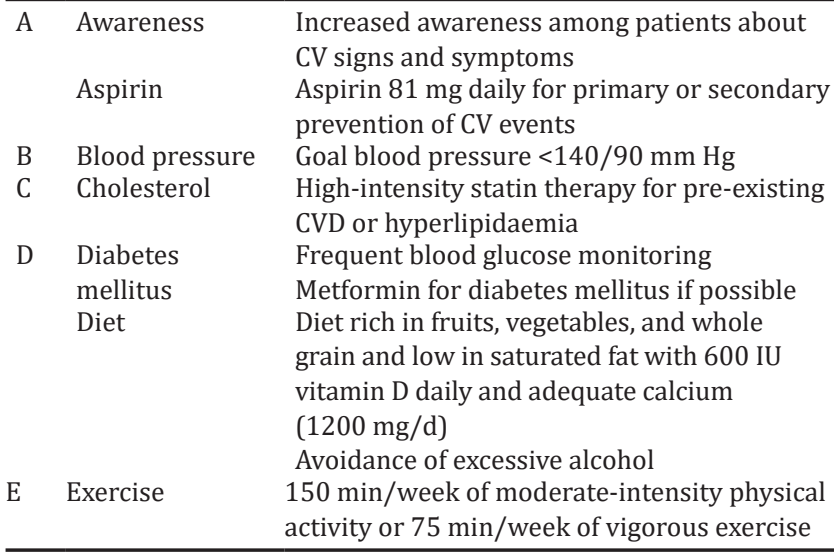

Source: American Heart Association, CVD: Cardiovascular disease

anti-hypertensives, OHA, and anti-platelets therapy, if necessary. ADT should not be given to prostate cancer patients who seem to have a history of CV problems [61]. Men with non-metastatic castrationresistant prostate cancer may be capable of minimizing their CV risk by identifying the appropriate therapy (e.g., using newer drugs such as androgen receptor inhibitors) [62]. A study conducted at a communitybased practice in the United States discovered that for men with clinically localized prostate cancer and a history of congestive heart failure or MI, treatment with ADT and radiation was associated with a higher all-cause mortality than treatment with radiation alone [63]. AHA recommended steps to reduce CV risk in patients with prostate cancer are elaborated in Table 2 [52].

\section{CONCLUSION}

Despite the adverse events, ADT remains as the first line therapy for patients with advanced prostate cancer. Many studies provide a positive relationship between $\mathrm{ADT}$ and $\mathrm{CV}$ morbidity, although some show no relationship. All patients receiving ADT, including those with pre-existing CV disease, must be evaluated for CV risk factors. As, under-recognition of risk factors and subsequent under treatment may represent an impaired quality of care in survivor populations. Furthermore, there is no evidence providing appropriate and potential treatment options. Some provide prophylactic treatment and, others with supportive management. Further studies should focus both on definite treatment options and on risk factors so to improve care in this population with definite preventive treatment.

\section{ACKNOWLEDGMENTS}

Declared none.

\section{AUTHORS' CONTRIBUTIONS}

All authors have contributed equally.

\section{CONFLICTS OF INTERESTS}

Author declares no conflicts of interests.

FUNDING

Nil.

\section{REFERENCES}

1. Zhu Y, Mo M, Wei Y, Wu J, Pan J, Freedland SJ, et al. Epidemiology and genomics of prostate cancer in Asian men. Nat Rev Urol 2021;2021:1-20

2. Ferlay J, Shin HR, Bray F, Forman D, Mathers C, Parkin DM. Estimates of worldwide burden of cancer in 2008: GLOBOCAN 2008. Int J
Cancer 2010;127:2893-917.

3. Rani P, Singh K, Arjuna A, Devi S. Detection of prostate cancer: A review. Asian J Pharm Clin Res 2018;11:25-1.

4. Center MM, Jemal A, Lortet-Tieulent J, Ward E, Ferlay J, Brawley O, et al. International variation in prostate cancer incidence and mortality rates. Eur Urol 2012;61:1079-92.

5. Hariharan K, Padmanabha V. Demography and disease characteristics of prostate cancer in India. Indian J Urol 2016;32:103.

6. SEER Cancer Statistics Review, 1975-2013. Bethesda, MD: National Cancer Institute; 2016. Available from: https://www.seer.cancer.gov/ csr/1975_2015; Available from: https://www.seer.cancer.gov/explorer/ application.php. [Last accessed on 2019 Feb 04].

7. Chen FZ, Zhao XK. Prostate cancer: Current treatment and prevention strategies. Iran Red Crescent Med J 2013;15:279.

8. Gasnier A, Parvizi N. Updates on the diagnosis and treatment of prostate cancer. Br J Radiol 2017;90:20170180.

9. Pirtskhalaishvili G, Hrebinko RL, Nelson JB. The treatment of prostate cancer. An overview of current options. Cancer Pract 2001;9:295-306.

10. Nevedomskaya E, Baumgart SJ, Haendler B. Recent advances in prostate cancer treatment and drug discovery. Int J Mol Sci 2018;19:1359.

11. Kumar S, Shelley M, Harrison C, Coles B, Wilt TJ, Mason M. Neo-adjuvant and adjuvant hormone therapy for localised and locally advanced prostate cancer. Cochrane Database Syst Rev 2006;4:CD006019.

12. Smith MR. Androgen deprivation therapy for prostate cancer: New concepts and concerns. Curr Opin Endocrinol Diabetes Obes 2007; $14: 247$.

13. DiPiro JT, Yee GC, Posey LM, Haines ST, Nolin YD, Ellingrod V.

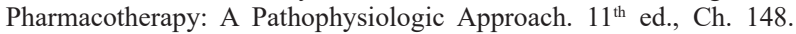
New York: McGraw-Hill Education; 2020. p. 6604-49.

14. Lester JF, Mason MD. Cardiovascular effects of hormone therapy for prostate cancer. Drug Healthc Patient Saf 2015;7:129.

15. Nguyen PL, Alibhai SM, Basaria S, D'Amico AV, Kantoff PW, Keating NL, et al. Adverse effects of androgen deprivation therapy and strategies to mitigate them. Eur Urol 2015;67:825-36.

16. Keating NL, O'Malley AJ, Smith MR. Diabetes and cardiovascular disease during androgen deprivation therapy for prostate cancer. J Clin Oncol 2006;24:4448-56.

17. US Food and Drug Administration. FDA Drug Safety Communication: Update to Ongoing Safety Review of GnRH Agonists and Notification to Manufacturers of GnRH Agonists to Add New Safety Information to Labeling Regarding Increased Risk of Diabetes and Certain Cardiovascular Diseases. Silver Spring, MD: US Food and Drug Administration; 2010.

18. Nassar GN, Leslie SW. Physiology, Testosterone. Treasure Island, FL: StatPearls; 2021.

19. Bilińska B, Wiszniewska B, Kosiniak-Kamysz K, Kotula-Balak M, Gancarczyk M, Hejmej A, et al. Hormonal status of male reproductive system: Androgens and estrogens in the testis and epididymis. In vivo and in vitro approaches. Reprod Biol 2006;6 Suppl 1:43-58.

20. Wilczynski C, Agrawal LL. Testosterone effects on the prostate gland: Review of pathophysiology and considerations in prostate cancer. J Fam Med Dis Prev 2015;1:4.

21. Huggins C, Stevens RB, Hodges CV. The effects of castration on advanced carcinoma of the prostate gland. Arch Surg 1941;43:209-3.

22. Chistiakov DA, Myasoedova VA, Melnichenko AA, Grechko AV, Orekhov AN. Role of androgens in cardiovascular pathology. Vasc Health Risk Manage 2018;14:283.

23. Ng CF, Chiu PK, Yee CH, Lau BS, Leung SC, Teoh JY. Effect of androgen deprivation therapy on cardiovascular function in Chinese patients with advanced prostate cancer: A prospective cohort study. Sci Rep 2020;10:1-9.

24. Dockery FM, Bulpitt CJ, Agarwal S, Donaldson M, Rajkumar C. Testosterone suppression in men with prostate cancer leads to an increase in arterial stiffness and hyperinsulinaemia. Clin Sci 2003;104:195-201.

25. Roe M. Assessment of Cardiovascular Risk with the Use of Androgen Deprivation Therapy for Prostate Cancer. Everyday 16; 2017.

26. Smith MR, Lee H, McGovern F, Fallon MA, Goode M, Zietman AL, et al. Metabolic changes during gonadotropin-releasing hormone agonist therapy for prostate cancer: Differences from the classic metabolic syndrome. Cancer 2008;112:2188-94.

27. Perlmutter MA, Lepor H. Androgen deprivation therapy in the treatment of advanced prostate cancer. Rev Urol 2007;9 Suppl 1:S3.

28. Rice MA, Malhotra SV, Stoyanova T. Second-generation antiandrogens: From discovery to standard of care in castration resistant prostate cancer. Front Oncol 2019;9:801.

29. Mitka M. New basic care goals seek to rein in global rise in 
cardiovascular disease. JAMA 2012;308:1725-6.

30. Zareba P, Duivenvoorden W, Leong DP, Pinthus JH. Androgen deprivation therapy and cardiovascular disease: What is the linking mechanism? Ther Adv Urol 2016;8:118-29.

31. Isbarn H, Boccon-Gibod L, Carroll PR, Montorsi F, Schulman C, Smith MR, et al. Androgen deprivation therapy for the treatment of prostate cancer: Consider both benefits and risks. Eur Urol 2009;55:62-75.

32. Perrone V, Esposti LD, Giacomini E, Veronesi C, Blini V, Oderda M. Cardiovascular risk profile in prostate cancer patients treated with GnRH agonists versus antagonists: An Italian real-world analysis. Ther Clin Risk Manage 2020;16:393.

33. Saigal CS, Gore JL, Krupski TL, Hanley J, Schonlau M, Litwin MS. Androgen deprivation therapy increases cardiovascular morbidity in men with prostate cancer. Cancer 2007;110:1493-500.

34. Tsai HK, D'Amico AV, Sadetsky N, Chen MH, Carroll PR. Androgen deprivation therapy for localized prostate cancer and the risk of cardiovascular mortality. J Natl Cancer Inst 2007;99:1516-24.

35. Alibhai SM, Duong-Hua M, Sutradhar R, Fleshner NE, Warde P, Cheung AM, et al. Impact of androgen deprivation therapy on cardiovascular disease and diabetes. J Clin Oncol 2009;27:3452.

36. Collier A, Ghosh S, McGlynn B, Hollins G. Prostate cancer, androgen deprivation therapy, obesity, the metabolic syndrome, Type 2 diabetes, and cardiovascular disease: A review. Am J Clin Oncol 2012;35:504-9.

37. Garnick MB, Pratt CM, Campion M, Shipley J. The effect of hormonal therapy for prostate cancer on the electrocardiographic QT interval: Phase 3 results following treatment with leuprolide and goserelin, alone or with bicalutamide, and the GnRH antagonist abarelix. J Clin Oncol 2004;22 Suppl 14:4578.

38. Bosco C, Bosnyak Z, Malmberg A, Adolfsson J, Keating NL, Van Hemelrijck M. Quantifying observational evidence for risk of fatal and nonfatal cardiovascular disease following androgen deprivation therapy for prostate cancer: A meta-analysis. Eur Urol 2015;68:386-96.

39. Dockery F, Bulpitt CJ, Agarwal S, Vernon C, Nihoyannopoulos P, Kemp M, et al. Anti-androgens increase N-terminal pro-BNP levels in men with prostate cancer. Clin Endocrinol 2008;68:59-65.

40. Moreira RB, Debiasi M, Francini E, Nuzzo PV, De Velasco G, Maluf FC, et al. Differential side effects profile in patients with mCRPC treated with abiraterone or enzalutamide: A meta-analysis of randomized controlled trials. Oncotarget 2017;8:84572.

41. Nelson CJ, Lee JS, Gamboa MC, Roth AJ. Cognitive effects of hormone therapy in men with prostate cancer: A review. Cancer 2008;113:1097-106.

42. Sun N, Xi Y, Jing S, Lu X. Morning blood pressure surge varies with age and gender in hypertensive individuals. Int J Cardiol 2009;135:272-3

43. Sasaki R, Yamano S, Yamamoto Y, Minami S, Yamamoto J, Nakashima T, et al. Vascular remodeling of the carotid artery in patients with untreated essential hypertension increases with age. Hypertens Res 2002;25:373-9.

44. Ashman JJ, Rui P, Schappert SM. Age Differences in Visits to Officebased Physicians by Adults with Hypertension. United States: US Department of Health and Human Services, Centers for Disease Control and Prevention, National Center for Health Statistics; 2016.

45. Amery A, Wasir H, Bulpitt C, Conway J, Fagard R, Lijnen P, et al. Aging and the cardiovascular system. Acta Cardiol 1978;33:443-67.

46. Roger VL, Go AS, Lloyd-Jones DM, Adams RJ, Berry JD, Brown TM, et al. Executive summary: Heart disease and stroke statistics 2011 update: A report from the American heart association. Circulation 2011;123:459-63.

47. Fathima M, Najeeb S, Fatima S, Khalid SM, Nikhat SR, Rao RC. A prospective observational study on risk factors and management of stroke at a tertiary care teaching hospital. Int J Pharm Pharm Sci 2018;10:24983.
48. Iacovelli R, Ciccarese C, Bria E, Romano M, Fantinel E, Bimbatti D, et al. The cardiovascular toxicity of abiraterone and enzalutamide in prostate cancer. Clin Genitourin Cancer 2018;16:e645-53.

49. Keating NL, O'Malley AJ, Freedland SJ, Smith MR. Diabetes and cardiovascular disease during androgen deprivation therapy: Observational study of veterans with prostate cancer. J Natl Cancer Inst 2010;102:39-46.

50. D'Amico AV, Denham JW, Crook J, Chen MH, Goldhaber SZ, Lamb DS, et al. Influence of androgen suppression therapy for prostate cancer on the frequency and timing of fatal myocardial infarctions. J Clin Oncol 2007:25:2420-5.

51. Azoulay L, Yin H, Benayoun S, Renoux C, Boivin JF, Suissa S. Androgen-deprivation therapy and the risk of stroke in patients with prostate cancer. Eur Urol 2011;60:1244-50.

52. Liu R, Zhou J, Xia S, Li T. Androgen deprivation therapy and the risk of stroke in patients with prostate cancer: An updated systematic review and meta-analysis. Urol Int 2020;104:214-21

53. Thomsen FB, Sandin F, Garmo H, Lissbrant IF, Ahlgren G, Van Hemelrijck M, et al. Gonadotropin-releasing hormone agonists, orchiectomy, and risk of cardiovascular disease: Semi-ecologic, nationwide, population-based study. Eur Urol 2017;72:920-8.

54. Tivesten $\AA$, Pinthus JH, Clarke N, Duivenvoorden W, Nilsson J. Cardiovascular risk with androgen deprivation therapy for prostate cancer: Potential mechanisms. In: Urologic Oncology: Seminars and Original Investigations. Vol. 33. Amsterdam, Netherlands: Elsevier; 2015. p. 464-75.

55. Levine GN, D'Amico AV, Berger P, Clark PE, Eckel RH, Keating NL, et al. Androgen-deprivation therapy in prostate cancer and cardiovascular risk: A science advisory from the American heart association, American cancer society and American urological association: Endorsed by the American society for radiation Oncology. Circulation 2010;121:833-40.

56. Schmidt B, Eapen RS, Cowan JE, Broering JM, Greene KL, Carroll PR, et al. Practice patterns of primary EBRT with and without ADT in prostate cancer treatment. Prost Cancer Prostat Dis 2019;22:117-24.

57. Taylor LG, Canfield SE, Du XL. Review of major adverse effects of androgen-deprivation therapy in men with prostate cancer. Cancer 2009;115:2388-99

58. Tanaka G, Hirata Y, Goldenberg SL, Bruchovsky N, Aihara K. Mathematical modelling of prostate cancer growth and its application to hormone therapy. Philos Trans R Soc A Math Phys Eng Sci 2010;368:5029-44.

59. Carroll PH, Mohler JL. NCCN guidelines updates: Prostate cancer and prostate cancer early detection. J Natl Compr Cancer Netw 2018;16:620-3.

60. Virgo KS, Rumble RB, de Wit R, Mendelson DS, Smith TJ, Taplin ME, et al. Initial management of noncastrate advanced, recurrent, or metastatic prostate cancer: ASCO guideline update. J Clin Oncol 2021;39:1274-305

61. Van Poppel H, Tombal B. Cardiovascular risk during hormonal treatment in patients with prostate cancer. Cancer Manage Res 2011;3:49.

62. Morgans AK, Shore N, Cope D, McNatty A, Moslehi J, Gomella L, et al. Androgen receptor inhibitor treatments: Cardiovascular adverse events and comorbidity considerations in patients with non-metastatic prostate cancer. In: Urologic Oncology: Seminars and Original Investigations. Amsterdam, Netherlands: Elsevier; 2020.

63. Nguyen PL, Chen MH, Beckman JA, Beard CJ, Martin NE, Choueiri TK, et al. Influence of androgen deprivation therapy on allcause mortality in men with high-risk prostate cancer and a history of congestive heart failure or myocardial infarction. Int J Radiat Oncol Biol Phys 2012;82:1411-6. 